\title{
In Vitro Culture of Zygotic Embryos of Taxus Species
}

\author{
Paula P. Chee \\ Molecular Biology Division, Unit 7242, The Upjohn Company, 301 Henrietta \\ Street, Kalamazoo, MI 49007
}

Additional index words. germination, regeneration, seed dormancy, tissue culture, yew trees, taxol plant

\begin{abstract}
An embryo culture method overcomes the lengthy dormancy requirement of Taxus L. spp. (yew) seeds. When zygotic embryos excised from mature T. brevifolia L. seeds were cultured in darkness for 4 weeks on one of three basal salt media (B5, Litvay, and Murashige and Skoog), radicle emergence and seedling development was highest on B5 basal salt medium. After 1 to 2 weeks on $B 5$ basal salt medium, seedling development of T. brevifolia, T. cuspidata L., T. baccata L., and T. baccata stricta L. ranged from $2 \%$ to $36 \%$. BA at $2.25 \mu \mathrm{M}$ had no effect on radicle emergence; $22.5 \mu \mathrm{M}$ prevented it. Embryos excised from mature or nearly mature seeds had the highest frequency of radicle emergence and seedling development. Cultured embryos developed seedlings in only 8 to 10 weeks. Chemical name used: $N^{6}$-benzyladenine (BA).
\end{abstract}

Taxus brevifolia is a slow-growing evergreen species occurring primarily in ancient forests of the Pacific Northwest in the United States. Interest in the culture of this and other Taxus species has intensified with the discovery of taxol, an anticancer drug found in various parts of the tree (Vidensek et al., 1990; Witherup et al., 1990). The total synthesis of taxol has recently been reported (Nicolaou et al., 1994); however, because of the complexity and numerous steps involved, large-scale synthesis is not now feasible.

Because $T$. brevifolia grows slowly and has a lengthy seed dormancy requirement ( 1.5 to 2 years), the supply of taxol is limited (Steinfeld, 1992). Embryo culture may overcome the problems posed by lengthy dormancy (Collins and Grosser, 1984). Flores and Sgrignoli (1991) reported an embryo culture method for Taxus that could overcome the dormancy requirement. However, their method was based on experiments that included few excised zygotic embryos. Therefore, the objective of the present research was to evaluate the response of excised T. brevifolia embryos to three basal salt culture media, i.e., B5 (Gamborg et al., 1968), LV (Litvay et al., 1985), and MS (Murashige and Skoog, 1962). Two additional objectives were to determine embryo responses of $T$. brevifolia, $T$. cuspidata, T. baccata, and T. baccata stricta in B5 culture medium, and whether seed maturity influences the frequency of radicle emergence and seedling development in Taxus.

\section{Materials and Methods}

Plant material and embryo isolation. Mature T. baccata, T. cuspidata, and T. baccata

Receivedforpublication12Oct. 1993. Accepted for publication 18 Mar. 1994. I thank Thomas Vilmar forassistance regarding statistical analysis of data. The cost of publishing this paper was defrayed in part by the payment of page charges, Under postal regulations, this paper therefore must be hereby marked advertisement solely to indicate this fact. stricta seeds were supplied by F.W. Schumacher Co., Sandwich, Mass. Taxus brevifolia seeds were provided by Special Trees, Portland, Ore. Seeds were surface-sterilized for $10 \mathrm{~min}$ in concentrated $\mathrm{HC} 1$, and then rinsed five times in sterile, distilled water. After sterilization, seeds were soaked in sterile, distilled water for $24 \mathrm{~h}$. Embryos were excised aseptically from surrounding gametophytic tissue under a binocular microscope using fine forceps and a scalpel.

Embryo culture. Zygotic embryos were cultured on B5, LV, or MS basal medium. All basal salt media were supplemented with $3 \%$ sucrose and solidified with $0.7 \%$ Phytagar (Gibco-BRL, Gaithersburg, Md.). In experiments where the effects of a growth regulator on embryo germination were studied, embryos were cultured on B5 basal medium supplemented with BA at $0,2.25$, or $22.5 \mu \mathrm{M}$. The $\mathrm{pH}$ of all media was adjusted to 5.8 before autoclaving at $121 \mathrm{C}$ for $20 \mathrm{~min}$. Generally, 20 embryos were placed in a $100 \times 20$-mm petri dish containing $25 \mathrm{ml}$ of culture medium. In cases where 20 embryos were not obtainable, some replicate dishes contained either more or fewer embryos. After transferring embryos to nutrient media, petri dishes were sealed with parafilm and incubated for 4 weeks at $26 \mathrm{C}$ in darkness. Subsequently, cultures were transfer-red to fresh medium of the same formulation and maintained under a $16-\mathrm{h}$ photoperiod provided by cool-white fluorescent lamps ( 80 $\left.\mu \mathrm{mol} \cdot \mathrm{m}^{-2} \cdot \mathrm{s}^{-1}\right)$. Seedlings were transferred to soil after they developed leaves and branched root systems.

Developmental stages of seeds. Seed maturity was classified into three stages according to the color of the seeds and status of fleshy long and light to medium green; the pre-aril sheath of young seeds was unswollen and green. Stage II (intermediate seeds): seeds were $\approx 4 \mathrm{~mm}$ long and dark green or light brown; the pre-aril sheath had begun to swell and was light pink. Stage III (mature seeds): arils. Stage I (young seeds): seeds were $\approx 2 \mathrm{~mm}$ seeds were $\approx 6 \mathrm{~mm}$ long and brown; the aril was swollen and red.

Statistical analyses. Germination or breaking dormancy was defined as radicle emergence, accompanied by embryo greening and elongation. Percent seedling development was defined as the number of embryos that ultimately developed into seedlings. The total number of embryos cultured in each treatment of each experiment is reported in Tables 1-5. For each treatment, data were entered into a contingency table. The response or nonresponse of different treatment groups was compared using the statistical procedure CATMOD (SAS Institute, 1989).

\section{Results and Discussion}

Formulation of basal salt. Radicle emergence frequency of $T$. brevifolia embryos cultured on B5, LV, and MS basal salts media was between $50 \%$ and $60 \%$ (differences nonsignificant), but final seedling development was lowest with LV, with MS being intermediate (Table 1). The effectiveness of the tested media on plant development was ranked as B5 > $\mathrm{MS}>\mathrm{LV}$.

Light vs. darkness. Radicle emergence of excised T. baccata stricta embryos was not affected by light; $T$. baccata radicle emergence was superior in darkness (Table 2). Darkness effected a greater response on seedling development for both species. Overall, $T$.

Table 1. Radicle emergence and seedling development of Taxus brevifolia embryos cultured on B5, LV, and MS basal salt media.

\begin{tabular}{lccc}
\hline \hline & $\begin{array}{c}\text { No. } \\
\text { embryos }\end{array}$ & $\begin{array}{c}\text { Radicle } \\
\text { emergence } \\
(\%)^{y}\end{array}$ & $\begin{array}{c}\text { Seedling } \\
\text { development } \\
(\%)^{x}\end{array}$ \\
\hline Medium $^{x}$ & 118 & 58 & 36 \\
B5 & 127 & 56 & 2 \\
MS & 106 & 53 & 20 \\
\hline
\end{tabular}

${ }^{2}$ B5 (Gamborg B5), LV (Litvay), MS (Murashige and Skoog).

${ }^{y}$ B5 vs. $\mathrm{LV}\left(\chi^{2}=0.07, P=0.79\right)$; B5 vs. MS $\left(\chi^{2}=\right.$ $0.52, P=0.47)$; LV vs. MS $\left(\chi^{2}=0.22, P=0.64\right)$.

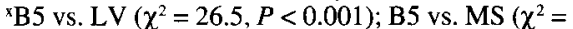
$7.4, P=0.01) ;$ LV vs. MS $\left(\chi^{2}=13.5, P<0.001\right)$.

Table 2. Comparison of radicle emergence and seedling development of Taxus baccata stricta and $T$. baccata embryos under light and in darkness.

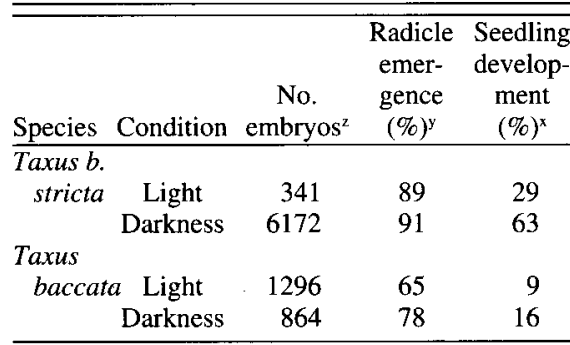

${ }^{2}$ Embryos cultured 4 weeks on B5 basal salt medium under light (16-h photoperiod) or in darkness for 4 weeks; subsequently, all cultures transferred to a 16 $\mathrm{h}$ photoperiod.

'Light vs. dark: $T . b$. stricta $\left(\chi^{2}=1.35, P=0.25\right) ; T$. baccata $\left(\chi^{2}=41.5, P<0.001\right)$.

${ }^{x}$ Light vs. dark: T. b. stricta $\left(\chi^{2}=136.2, P<0.001\right)$; T. baccata $\left(\chi^{2}=23.4, P<0.001\right)$. 


\section{Rapid Communication}

Table 3. Radicle emergence of Taxus cuspidata embryos cultured on B5 basal medium with or without BA.

\begin{tabular}{lcc}
$\begin{array}{l}\text { Culture } \\
\text { medium }\end{array}$ & $\begin{array}{c}\text { No. } \\
\text { embryos }\end{array}$ & $\begin{array}{c}\text { Radicle } \\
\text { emergence } \\
(\%)^{2}\end{array}$ \\
\hline B5 & 184 & 41 \\
B5 + BA $(2.25 \mu \mathrm{M})$ & 231 & 39 \\
B5 + BA $(22.5 \mu \mathrm{M})$ & 200 & 0 \\
\hline
\end{tabular}

${ }^{2} \mathrm{~B} 5$ vs. B5 + BA $(2.25 \mu \mathrm{M})\left(\chi^{2}=0.33, P=0.57\right) ; \mathrm{B} 5$ vs. B5 + BA $(22.5 \mu \mathrm{M})\left(\chi^{2}=15.08, P<0.001\right)$.

baccata stricta responded better than $T$. baccata $\left(x^{2}=156, P 0.001\right)$ with respect to radicle emergence and seedling production.

Growth regulator. In many cases, exogenously supplied growth regulators are not required for embryo culture. Monnier (1978) suggested that embryos can be considered plants with their own endogenous hormones. However, there are several cases in which adding either cytokinin, auxin, or gibberellin has greatly facilitated embryo culture (Collins and Grosser, 1984). Radicle emergence of $T$. cuspidata embryos on B5 was similar with or without $2.25 \mu \mathrm{M}$ BA; however, no radicles emerged on B5 + $22.5 \mu \mathrm{M}$ BA (Table 3 ).

Species comparison. Embryos from $T$. brevifolia, T. baccata, T. baccata stricta, and T. cuspidata seeds cultured on B5 appeared similar after 1 week of incubation (Fig. 1A). After this period, embryos from all species
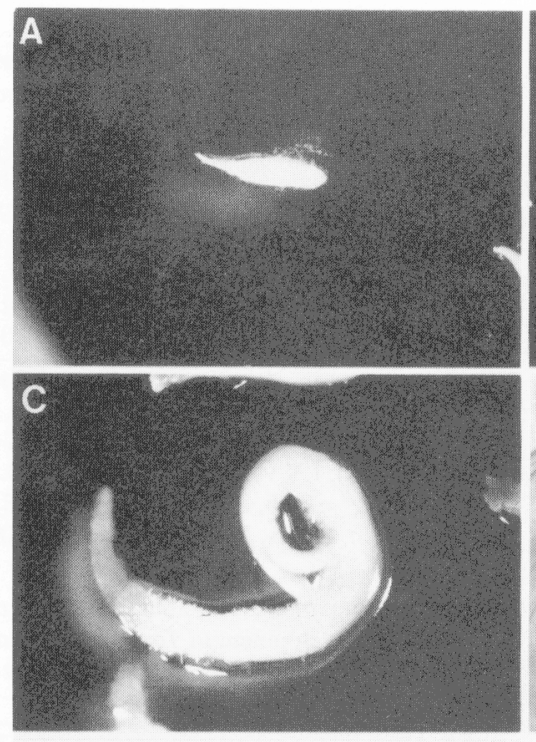

E

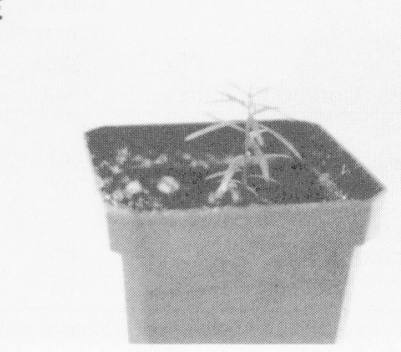

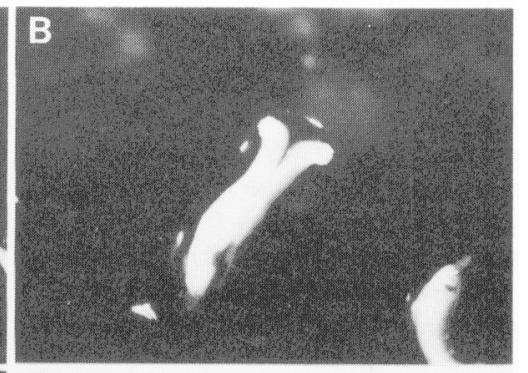

Table 4. Radicle emergence and seedling development of embryos from various Taxus species cultured on B5 medium.

\begin{tabular}{lccc}
\hline Species & $\begin{array}{c}\text { No. } \\
\text { embryos }\end{array}$ & $\begin{array}{c}\text { Radicle } \\
\text { emergence } \\
(\%)^{\mathrm{z}}\end{array}$ & $\begin{array}{c}\text { Seedling } \\
\text { development } \\
(\%)^{\mathrm{y}}\end{array}$ \\
\hline T. brevifolia & 3,541 & 61 & 14 \\
T. cuspidata & 3,553 & 64 & 14 \\
$T$. baccata & 3,800, & 58 & 17 \\
$T$. baccata & & & \\
stricta & 19,784 & 63 & 11
\end{tabular}

${ }^{2}$ Taxus brevifolia vs. $T$. cuspidata $\left(\chi^{2}=6.8, P=\right.$ $0.01) ; T$. brevifolia vs. $T$. baccata $\left(\chi^{2}=6.8, P=\right.$ $0.01) ;$ T. brevifolia vs. T. $b$. stricta $\left(\chi^{2}=5.1, P=\right.$ $0.02) ; T$. cuspidata vs. $T$. baccata $\left(\chi^{2}=27.7, P<\right.$ $0.001) ; T$. cuspidata vs. $T$. b. stricta $\left(\chi^{2}=1.3, P=\right.$ $0.25) ;$ T. baccata vs. T. b. stricta $\left(\chi^{2}=33.3, P<\right.$ 0.001 ).

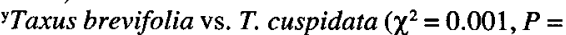
$0.98) ;$ T. brevifolia vs. T. baccata $\left(\chi^{2}=12.5, P<\right.$ $0.001) ; T$. brevifolia vs. T. $b$. stricta $\left(\chi^{2}=26.7\right.$, $P<0.001) ; T$. cuspidata vs. T. baccata $\left(\chi^{2}=\right.$ $12.7, P<0.001)$; T. cuspidata vs. T. b. stricta $\left(\chi^{2}=\right.$ 26.4, $P<0.001) ;$. baccata vs. $T$. $b$. stricta $\left(\chi^{2}=\right.$ 107.2, $P<0.001$ ).

began to enlarge (Fig. $1 \mathrm{~B}$ and $\mathrm{C}$ ), and radicles had emerged by the end of 4 weeks. Radicle growth of embryos within a species was not synchronized, and showed much variation in morphology and size. Excised embryos did not turn brown. Most seedlings had a single, slender primary root with secondary roots developing from these primary roots during
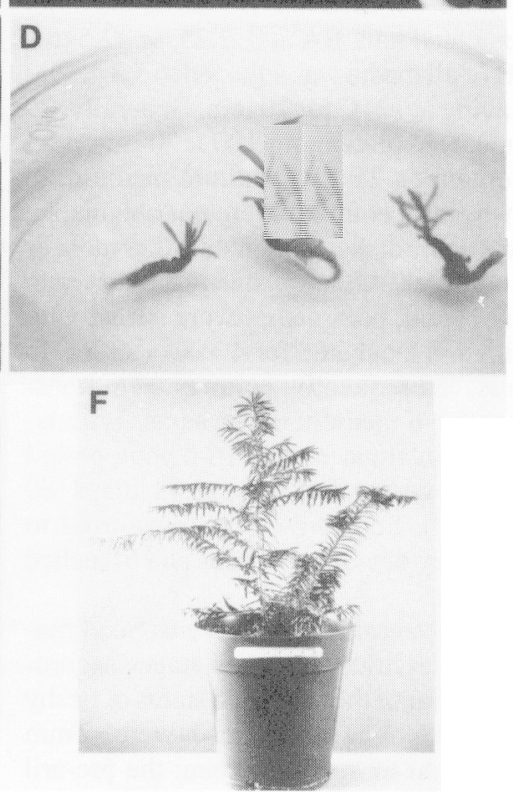

Fig. 1. Embryo culture of Taxus brevifolia. Embryos were excised from mature seeds of T. brevifolia and cultured on B5 basal salt medium. (A) One-day-old embryo culture, $2 \mathrm{~mm}$ long. (B) Two-week-old embryo culture, $5 \mathrm{~mm}$ long. (C) Three-week-old embryo culture. (D) Regenerated 2-month-old seedling from embryo culture. (E) Three-month-old seedling. (F) Two-year-old plant.
Table 5. Taxus brevifolia radicle emergence and seedling development of embryos from seeds of different developmental stages cultured on B5 and MS basal salt media.

\begin{tabular}{lcccc}
\hline \hline Stage & $\begin{array}{c}\text { Basal } \\
\text { salt }\end{array}$ & $\begin{array}{c}\text { No. } \\
\text { embryos }^{z}\end{array}$ & $\begin{array}{c}\text { Radicle } \\
\text { emer- } \\
\text { gence } \\
(\%)^{y}\end{array}$ & $\begin{array}{c}\text { Seedling } \\
\text { develop- } \\
\text { ment } \\
(\%)^{x}\end{array}$ \\
\hline I & B5 & 40 & 0 & 0 \\
& MS & 20 & 0 & 0 \\
II & B5 & 1900 & 26 & 21 \\
& MS & 960 & 24 & 15 \\
III & B5 & 1680 & 69 & 52 \\
& MS & 1380 & 52 & 31
\end{tabular}

${ }^{\mathrm{z}}$ Stage II, B5 vs. MS $\left(\chi^{2}=1.4, P=0.24\right)$; stage III, B5 vs. MS $\left(\chi^{2}=136.5, P<0.001\right)$.

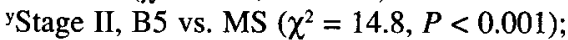
stage III, B5 ys. MS $\left(\chi^{2}=135.3, P<0.001\right)$.

the first two culture passages (Fig. 1D). Plants derived from embryo culture were vigorous and adapted to transplant within a few days (Fig. 1E). Radicle emergence after 4 weeks for the four species ranged from $58 \%$ to $64 \%$, and $11 \%$ to $17 \%$ developed into seedlings (Table 4).

Development stages of seeds. Developmental stage of the excised embryo has an important effect on germination frequency (Table 5). Embryos from stage I seeds did not survive in culture, but radicles emerged and seedlings developed from embryos of stage II and III seeds, with best results from the more mature seeds.

The interaction between maturity stage of seeds and basal salt formulation was highly significant for stage II and III seeds $\left(x^{2}=\right.$ 29.47, $P \leq 0.001$ ) (Table 5). B5 and MS basal salts gave similar results for stage II seeds, but B5 produced significantly more germinating embryos with stage III seeds than did MS. Embryos of stage III seeds produced a higher percentage of germinating embryos than stage II seeds for both basal salts $(P<0.001$ in both cases). Embryos from stage II and III seeds had better seedling development on B5 than MS $(P \leq 0.001)$, which is consistent with data in Table 1.

Flores and Sgrignoli (1991) observed that germination frequencies of Taxus embryos depended on seed maturity; germination diminished to $0 \%$ as seeds reached maturity. Differences in results between the present study and the earlier one may be due to the use of different seed lots and culture media [Flores and Sgrignoli (1991) used White basal salt (White, 1934)].

Results herein indicate that lengthy seed dormancy of Taxus species can be overcome by culturing excised embryos from relatively mature seeds. The best culture condition was in B5 basal salt medium in darkness for 4 weeks and subsequent transfer to fresh medium under a 16-h photoperiod. Seedlings can be obtained in 8 to 10 weeks compared to 1 to 2 years for stratified seeds.

\section{Literature Cited}

Collins, G.B. and J.W. Grosser. 1984. Culture of embryos, p. 241-257. In: I.K. Vasil (cd.). Cell 
culture and somatic cell genetics of plants. vol. 1. Academic, New York.

Flores, H.E. and P.J. Sgrignoli. 1991. In vitro culture and precocious germination of Taxus embryos. In Vitro Cellular Developmental Biol. 27:139142 .

Gamborg, O. L., R.A. Miller, and K. Ojima. 1968. Nutrient requirements of suspension cultures of soybean root cells. Expt. Cell Res. 50:151158.

Litvay, J.D., D.C. Verma, and M.A. Johnson. 1985. Influence of a loblolly pine (Pinus taeda L.) culture medium and its components on growth and somatic embryogenesis of the wild carrot
(Daucus carota L.). Plant Cell Rpt. 4:325-328. Monnier, M. 1978. Culture of zygotic embryos, p. 277, In: T, A. Thorpe (ed.). Frontiers of plan tissue culture. Univ. of Calgary Press, Calgary, Canada.

Murashige, T. and F. Skoog. 1962. A revised medium for rapid growth and bioassays with tobacco tissue cultures. Physiol. Plant. 15:473479.

Nicolaou, K. C., et al. 1994. Total synthesis of taxol. Nature 375:630-634

SAS Institute. 1989. SAS/STAT user's guide, version 6. 4th ed. vol. 1. SAS Institute, Cary, N.C.

Steinfeld, D. 1992. Early lessons from propagating
Pacific yew. Rocky Mountain Forest \& Range Expt. Sta. Tech. Res. Rpt. 221.

Vidensek, N., P. Lim, A. Campbell, and C. Carlson. 1990. Taxol content in bark, wood, root, leaf, twig, and seedlings from several Taxus species. J. Natural Prod. 53:1609-1610.

White, P. 1934. Potentially unlimited growth of excised tomato root tips in a liquid medium. Plant Physiol. 9:585-600.

Witherup, K. M., S.A. Look, M.W. Stasko, T.J. Ghiorzi, and G.M. Muschik. 1990. Taxus spp. needles contain amounts of taxol comparable to the bark of Taxus brevifolia: Analysis and isolation. J. Natural Prod. 55: 1249-1255. 